\title{
Julinho da Adelaide, um pseudônimo que driblou a Censura \\ - em processo -
}

\section{Eugenio Brauner *}

\begin{abstract}
Resumo: A utilização de pseudônimo sempre acompanhou a história da literatura, marcando o trabalho de escritores dos mais variados gêneros. Chico Buarque escondeu-se por detrás de Julinho da Adelaide para fazer com que suas músicas passassem pelo crivo da Censura durante os anos de 1974 e 1975. Este trabalho visa estudar o caso Julinho da Adelaide, um nome que deixou de ser um simples pseudônimo para se tornar uma personagem - complexa e difusa daqueles tempos.
\end{abstract}

\begin{abstract}
The use of a pseudonymous has always been a practice in the history of literature, acting upon the work of writers from different genres. In 1974 and 1975, Chico Buarque took the cover of Julinho da Adelaide in order to make his songs be permitted by the censorship experts. This research aims at studying the case Julinho da Adelaide, a name that has turned from a simple pseudonymous into a complex and diffuse character of those times. inse character of those times.
\end{abstract}

Keywords: Chico Buarque; Julinho da Adelaide; Pseudonymous; Military dictatorship; Censorship.
Palavras-chave: Chico Buarque; Julinho da Adelaide; Pseudônimo; Ditadura militar; Censura

Pseudônimos e toda forma de disfarce sempre acompanharam a história da literatura, marcando o trabalho de escritores dos mais variados gêneros. E as razões que levam um escritor a se esconder por detrás da máscara de um outro nome são as mais diversas possíveis: caminham desde o anonimato debochado até a clandestinidade da escrita política e de contestação e é no contexto de repressão política que este ensaio irá abordar a pequena; porém, maiúscula obra de Julinho da Adelaide, um pseudônimo que acabou virando uma personagem daquele tempo.

Na literatura brasileira, a utilização de pseudônimos foi algo bastante comum. Os árcades contestaram a administração de Luís da Cunha Meneses, o governador da capitania de Minas Gerais, com Critilo enviando cartas para Doroteu - aquele, Tomás Antônio Gonzaga; este, Cláudio Manuel da Costa. José de Alencar assinou como IG a sua coluna no Diário do

\footnotetext{
* Eugenio Brauner é estudante do curso de Letras da UFRGS e pesquisador da FAPERGS no projeto "A Contribuição do Conto para uma Concepção de Identidade nas Literaturas Latino-Americanas", realizado na mesma universidade.
} 
Rio de Janeiro e Machado de Assis, no Jornal da Família, assinou como Lara as suas crônicas na segunda metade do século XIX. Até D. Pedro II, defendendo a abolição da escravatura, se valeu de pseudônimo - criativo, por sinal - para publicar suas posições na imprensa carioca: assinava ele como "Piolho Viajante".

Em 1933, Patrícia Galvão lançou uma edição limitada e quase clandestina de Parque Industrial sob o pseudônimo de Mara Lobo, por exigência do Partido Comunista, do qual ela era militante na época. Além de publicar contos na revista Detective, editada por Nélson Rodrigues, entre julho e dezembro de 1944, por detrás do nome de King Shelter.

No início da sua carreira jornalística, Carlos Drummond de Andrade usou o pseudônimo de Antônio Crispim; porém, quando fazia críticas de cinema, adotava os nomes de Mickey ou Gato Félix. Entre os anos de 1944 e 1947, Nélson Rodrigues sacudiu a sociedade carioca com peças assinadas sob o pseudônimo de Suzana Flag. No início dos anos 50, Sérgio Porto - inspirado no personagem satírico Serafim Ponte Grande, de Oswald de Andrade - assinou como Stanislaw Ponte Preta enquanto trabalhava para o jornal Diário Carioca.

Temos, inclusive, histórias curiosas a respeito de pseudônimos, como é o caso do lançamento de $O$ Quinze, onde muitos acreditaram que Rachel de Queiroz era o pseudônimo de algum escritor. Inclusive Graciliano Ramos teimou, diante da linguagem do romance, e quase não aceitou a idéia de que o drama sobre a tão devastadora seca de 1915, no Ceará, tivesse sido escrito por uma mulher.

A literatura, assim como todas as artes, depende da ação de fatores do meio e que acabam por se exprimir na obra em graus variados de sublimação e, segundo Antonio Candido,

Produz sobre os indivíduos um efeito prático, modificando a sua conduta e concepção do mundo, ou reforçando neles o sentimento dos valores sociais. Isto decorre da própria natureza da obra e independe do grau de consciência que possam ter a respeito os artistas e os receptores de arte. (CANDIDO, 1976, p. 24)

A obra depende do artista e das condições sociais que determinam a sua posição. Ainda segundo Candido, ao artista estão relacionados apenas os aspectos estruturais, enquanto na obra focaliza-se "o influxo exercido pelos valores sociais, ideologias e sistemas de comunicação, que nela se transmudam em conteúdo e forma, discerníveis apenas logicamente, pois na realidade decorrem do impulso criador como unidade inseparável." (CANDIDO, 1976, p. 35).

Cabe aqui lembrar que os valores e as ideologias do artista contribuem para o conteúdo, principalmente, enquanto as modalidades de comunicação influenciam mais na 
forma. Lembrando a teoria determinista de Taine, acredito que Chico Buarque, ao ser forçado a criar um pseudônimo para si, fora influenciado pelo meio e pelo momento histórico em que estava inserido.

Um ponto fundamental que devemos esclarecer aqui: Julinho da Adelaide é tão somente um pseudônimo de Chico Buarque e não, como alguns críticos dizem, um heterônimo ou alter ego do compositor.

No primeiro caso - o heterônimo - cabe lembrar Fernando Pessoa e a sua genialidade que não cabia dentro de si e que, para tanto, acabou se desdobrando em Álvaro de Campos, Alberto Caeiro, Ricardo Reis e Bernardo Soares. Nas Páginas Íntimas, Fernando Pessoa escreveu:

A cada personalidade mais demorada, que o autor destes livros conseguiu viver dentro de si, ele deu uma índole expressiva, e fez dessa personalidade um autor, com um livro, ou livros, com as idéias, as emoções, e a arte dos quais, ele, o autor real (ou porventura aparente, porque não sabemos o que seja a realidade), nada tem, salvo o ter sido, no escrevê-las, o médium de figuras que ele criou" e mais adiante diz: "escravo como é da multiplicidade de si próprio" (PESSOA, 1998, p. 271-272).

Caso comparemos o cancioneiro de Chico Buarque com as músicas compostas sob o pseudônimo de Julinho da Adelaide - “Acorda Amor" (1974), "Jorge Maravilha” (1974) e "Milagre Brasileiro" (1975), não veremos nada de diferente em relação a "Apesar de Você" (1970), "Deus lhe Pague (1971)" e "Quando o Carnaval Chegar" (1972), já que todas elas possuem um forte apelo político, ou seja, ambos falam da mesma 'coisa' e do mesmo 'jeito', sem características distintas. Portanto, podemos confundir autor e obra, algo impensável quando tratamos de Fernando Pessoa.

No segundo caso - alter-ego - devemos lembrar que ego é o que pensamos de nós mesmos e este pensamento é o que orienta as nossas atitudes e ações - ele dita o que se deve fazer ou ser. Já o alter-ego é a modificação desse pensamento, ou seja, é o outro ego - uma dupla personalidade. Em uma entrevista concedida por Chico Buarque a Geraldo Leite em 1989, podemos ver claramente a consciência daquele a respeito da criação do pseudônimo:

aí eu senti que a barra estava pesada e falei: vamos experimentar com outro nome que pode ser que melhore. E realmente melhorou. As três primeiras músicas que mandei, onde eu assinava como Julinho da Adelaide, passaram. Se fossem com o meu nome, provavelmente, não passariam $^{1}$.

Portanto, Chico Buarque estava ciente do que fazia para driblar os censores e não que Julinho da Adelaide viesse a ser o seu alter-ego.

Em 1964 os militares tomam o poder. A linha dura começava, porém, somente quatro anos mais tarde, a falta de liberdade de expressão fora levada ao extremo com a instalação do 
Ato Institucional 5, o 'popular' AI-5, em 1968. Enfim, os militares declaravam a censura contra jornalistas, escritores, músicos - pessoas que tinham a opinião pública nas mãos e que tinham sido relativamente poupadas até o momento, já que, segundo Adélia Bezerra de Meneses, apenas os intelectuais que mantinham algum tipo de articulação com os movimentos operários e camponeses eram perseguidos até então. Chico Buarque de Holanda lembra da censura que estava sendo imposta aos seus trabalhos:

É evidente que, uma vez proibido, ficava marcado. Eu e outros autores, que tínhamos uma ou outra música proibida, ficávamos numa espécie de index da censura. Então a música que chegava com o meu nome chamava a atenção. E eu comecei a sofrer uns cortes bastante arbitrários.

Em 1974, Chico Buarque cria Julinho da Adelaide, pseudônimo que faz com que as músicas “Acorda Amor" (1974), "Jorge Maravilha” (1974) e "Milagre Brasileiro" (1975) todas elas de forte conteúdo político - passem pelos crivos dos censores. Somente assim, escondido por detrás de outro nome, para Chico conseguir driblar a censura, já que o próprio estava recebendo uma espécie de 'tratamento vip'. Ele chegou a afirmar nos jornais que, de cada três músicas enviadas para a Censura, somente uma era liberada. Em alguns casos a censura era política (como "Cálice", de 1973); em outros, de censura moral (como em "Não Existe Pecado ao Sul do Equador", de 1972/73) - reafirmando, segundo Bezerra de Meneses, O

fundamento do pensamento de Reich em Psicologias de Massas do Fascismo, onde se mostra com maior clareza a função política da repressão sexual, a relação íntima que liga a vida sexual e a intensidade do recalcamento sexual às concepções e inclinações da política reacionária (MENESES, 2000, p. 76)

Marina Brum Duarte, uma das censoras do compositor na década de 70, ilustra muito bem o embate travado na época, ao lembrar do que pensou enquanto barrava "Cálice" (1973): "Pensar que eu não ia deduzir que aquele cálice não era uma taça, e sim uma referência ao silêncio... francamente. O que ele achou? Que eu era trouxa?" Dona Marina - hoje com 83 anos - fala amargamente daqueles tempos de censora: "Fui uma rameira do sistema. Eu não condeno quem age em má situação financeira. Eu me vendi por dinheiro". Ela lembra ainda que "a censura foi eivada de coisas horrorosas" e que todas as músicas que eram assinadas por Chico Buarque eram duplamente analisadas, dissecadas palavra por palavra.

Em setembro de 1974, o jornal Última Hora publica uma entrevista exclusiva com Julinho da Adelaide - a única concedida por ele na sua breve e comentada carreira musical e que o alçava, enfim, ao nível de personagem daqueles anos.

\footnotetext{
${ }^{1}$ As citações sem referências foram retiradas do site http://www.chicobuarque.com.br
} 
Tudo começou com Mário Prata - jornalista, escritor e amigo de Chico Buarque - que propôs ao compositor de "Cordão" (1971) a idéia de criar uma entrevista com Julinho da Adelaide, figura que começava a ser comentada no meio artístico. Chico concordando, se uniu a dupla o também jornalista Melchíades Cunha Júnior e, assim, Julinho da Adelaide deixava de ser uma espécie de mito, já que mostrava a cara - ou melhor, não deixou mostrá-la devido a sua pretensa feiúra - e ganhava voz na mídia.

Falando em aparências, Chico Buarque faz de Julinho da Adelaide um espelho invertido de si próprio. Tudo que o primeiro não é (ou acha ser) é evidenciado ou ressaltado nas características do segundo, que começa a se configurar - a partir dessa entrevista - em uma espécie de personagem vivida e interpretada por Francisco Buarque de Holanda.

Chico Buarque, conhecido por arrancar suspiros femininos por onde passasse, faz de Julinho o compositor mais feio da MPB - com cicatrizes e tudo. Cicatrizes que são minuciosamente descritas a partir do episódio verídico em que Sérgio Ricardo joga o violão contra a platéia ao ser vaiado em um dos festivais da MPB: "o cabo pegou assim aqui e a caixa desse outro lado". E Julinho, ao contrário de Chico que estampava o seu rosto nos discos, não pretendia ter a sua foto na capa de um futuro LP.

Eu posso até gravar um disco um dia, entende? Aí a minha foto vai atrapalhar a vendagem do disco, não é? É claro que eu não vou botar na capa do disco a minha foto. Mas se já estiver a minha foto ligada a minha pessoa, amanhã, sei lá, menininhas dessas bonitas aí da Rua Augusta e tal que... podem comprar pensando que é um sujeito bonito e vende mais o disco, acho, não é? Pelo menos com a minha cara ligada a minha pessoa vende menos. Então, é melhor não ter cara do que ter a cara que eu tenho.

Outra característica que Chico Buarque cria em Julinho é a respeito da opinião e do posicionamento deste sobre o regime militar e a censura. Aqui está mais do que claro que, se Chico, através de Julinho, diz-se a favor dos censores, ganharia destes um olhar menos crítico e mais condescendente ou, simplesmente, simpático. Ou seja, Chico é um famoso contestador do sistema, enquanto Julinho é favorável à medida que deseja ascender profissionalmente.

Então com relação à censura eu tenho essa posição. Eu acho bobagem a pessoa falar que a censura prejudica, quando eu acho que o negócio é fazer samba, tem que fazer muito samba mesmo, entende? Eu faço muito samba, quer dizer, faço vários por dia mesmo. Tanto que o sujeito que trabalha lá, o trabalho dele é censurar música, eu respeito muito o trabalho do cara, quer dizer, ele terminou o dia... quantas músicas você censurou hoje? Ele fala: 7. O cara que disser 17, por exemplo, vai ser promovido logo. Eu também, meu trabalho é fazer samba, quantos samba você fez hoje? Oito, nove? No dia que eu faço dez vou dormir em paz com a minha consciência, entende? Cada um no seu ramo [...] O rapaz que trabalha na censura é um homem, pai de família e tem que trabalhar, (todos falam) como eu. Ele está lá cumprindo seu trabalho. Se ele parar de proibir, vai perder o emprego, porque fica um trabalho inútil. Assim como se eu parar de fazer samba, eu deixo de ser sambista. Então, o censurador deixa de ser censor quando ele parar de proibir. Então, vamos nos unir, né, num grande abraço. Então, o censor censura e a gente faz música e o censor censura e a gente faz música. 
Perguntado se já tinha alguma música vetada pela censura, Julinho responde, visivelmente para agradar àqueles que pregavam um maior engajamento político por parte dos artistas brasileiros na época, além é claro, de uma falsa modéstia: "Eu tenho, já te falei que tenho, mas eu tenho mais diálogo do que problema. Cada vez que surge um problema, para isso que eu fiz o samba duplex, que eu pretendo, inclusive, patentear [...] E depois eu acho que quem faz um samba, faz dez."

O samba duplex a que Julinho se refere, remete claramente às músicas de Chico Buarque que tiveram versos vetados, como em "Atrás da Porta" (1972) em que o verso "nos teus pêlos" mudou para "no teu peito", em "Não Existe Pecado ao Sul do Equador" (1972/73) em que o verso "Vamos fazer um pecado safado debaixo do meu cobertor" virou "Vamos fazer um pecado rasgado, suado, a todo vapor" ou em "Samba de Orly" (1970) que os versos "pela omissão" e "um tanto forçada" mudam, respectivamente, para "pela duração" e "dessa temporada".

Um dos motivos de Chico Buarque posicionar Julinho desta maneira é o fato de Leonel Paiva - irmão e procurador deste - ser uma espécie de malandro. Um malandro que tem influências e que transita, com respaldo, por outras camadas sociais. Assim, Julinho da Adelaide vale-se de Leonel para ser aceito no meio artístico, enquanto Leonel usa o talento do irmão para ascender financeiramente.

ele [Leonel] é muito ligado ao pessoal do Rio de Janeiro, Zózimo Barroso do Amaral, que trabalha no Jornal do Brasil. Ele é ligadíssimo. É como se fossem irmãos. Tem amigo que é dono de jornal, já falou de muita gente que ele é amigo... do Doc... Ele me promove, me promove muito. Ele é um cara $100 \%$. Vocês precisam conhecer ele.

Podemos ver aqui a tese que Roberto Schwarz chama, em linhas gerais, de "prática geral do favor". Bastante comum na sociedade brasileira do século XIX - e ainda bastante comum nos dias de hoje - e que, resumidamente, consiste na possibilidade de ascensão social.

O favor é, portanto, o mecanismo através do qual se reproduz uma das grandes classes da sociedade, envolvendo também outra, a dos que têm [...] como o profissional dependia do favor para o exercício da sua profissão, o pequeno proprietário depende dele para a segurança de sua propriedade, e o funcionário para o seu posto (SCHWARZ, 2003, p.16).

Numa clara crítica aos empresários que exploram o artista e ao artista que se deixa explorar pelo empresário, Chico Buarque promove um arrombo de inocência em Julinho da Adelaide. Porém é estranho que o compositor de "Milagre Brasileiro", com origens nas favelas da Rocinha e do Pinto e atual morador da Selva de Pedra - ou seja, um malandro do morro carioca - deixe-se enganar pelo irmão, sendo inclusive preso no lugar deste.

UH - Então já está pintando um dinheirinho?

JA - Diz o Leonel que sim. Eu ainda não pus a mão nesse dinheiro porque o Leonel tem procuração minha para fazer tudo. Ele acha que não é bom pegar o dinheiro e fazer logo 
alguma coisa. É melhor empregar e ele empregou meu dinheiro. E parece que o dinheiro já vai dar agora um dividendo, uma coisa assim...

UH - Mas, e aquela casa que você está construindo lá na Barra? É com dinheiro de vendagem? JA - Não sou eu que construí... Quem comprou um terreno na Barra foi o Leonel e vai construir uma casa lá. Mas isso é problema do Leonel, ele tem os bicos dele por fora. Leonel tem participação nos meus lucros e ele faz com o dinheiro dele o que ele bem entende... E só porque ele ganha 50\%. E dizem que os empresários normalmente têm 20 só. Aqui no Brasil, porque diz que lá fora tem dez. Agora, ele não é só um empresário. Se fosse só um empresário, tá legal, ganhava 20\%. Ele não é meu empresário. Ele é meu conselheiro e meu irmão, entende? Então, a gente divide irmamente as partes. Acho justo isso. E tem mais, ele ainda aplica nos mercados de capitais os meus lucros.

Julinho da Adelaide tenta não se comprometer com doutrinas ou pessoas, já que precisa delas para ascender socialmente. Indagado sobre quais notas daria para Nara Leão (cantora), Ibraim Sued (colunista social do jornal $O$ Globo), Gerald Ford (então presidente norte-americano) e Garrincha (ex-jogador de futebol), Julinho não vacila e dá nota dez a todos. Aqui cabe a sua explicação:

Garrincha... Garrincha eu não dou nota dez pra ele...Se bem que ele é casado com a Elza Soares, amanhã ela pode querer gravar um samba meu (risos), é bom a gente estar sempre... É isso que eu falei: Nara Leão vai gravar um samba meu, o Gerald Ford, o presidente, nota 10. Ele pode fazer um arranjo muito bom. O Ibraim Sued pode dar uma nota a meu respeito, não é? Nota 10. Agora, não publica isso que eu estou falando, as explicações das notas que estou dando não. Só põe as notas.

UH - Outra figura. Wilson Simonal.

JA - Nota 10.

UH - Eu estou achando você muito condescendente.

JA - Como?

UH - Você me perdoe, não me leve a mal, mas você não me parece ter uma posição política definida. Você me parece muito preocupado em colocar sua música no mercado...

[...]

UH - Ainda dentro daquela linha do nosso amigo aqui eu vou te pedir pra você dar notas pra três personalidades, Sabu...

JA - Sabu morreu, não é? Eu não achava ele muito bom ator, não. Nota quatro.

UH - Ainda mais agora, morto. (risos)

UH - Golbery

JA - Golbery, nota dez.

UH - Caetano Veloso

JA - Caetano Veloso, nota dez.

UH - Perfeito

JA - Eu não sou como aquela moça da televisão que dá 10 pra todo mundo. Você viu que pro Sabu eu dei nota 4 [...], e eu não achei ele muito bom ator não.

Além destes, aparecem ao longo da entrevista Dom e Ravel, Secos e Molhados, Benito de Paula - a nenhum deles Julinho deixa escapar alguma crítica, num claro jogo de interesse da sua parte, configurando-se em uma fina ironia na voz de Chico Buarque. Esta passagem ilustra bem o pensamento criado por Chico para Julinho da Adelaide:

como já disse antes, eu não sou cantor. Eu preciso dos cantores para lançar o meu nome. Acho que é um interesse recíproco. [...] Ele tá faturando em cima do meu nome e eu estou faturando em cima do dele [referência ao fato de Chico cantar as músicas de Julinho da Adelaide nos seus shows sem dar o crédito da sua autoria] [...] Eu preciso dele, ele precisa de mim. Não adianta você me dizer isso, parece que está me colocando contra ele. No dia em que eu for conhecido e famoso talvez eu faça dele a mesma coisa, entende? As pessoas têm que tirar proveito do que lhe cai na mão. O Leonel que me disse isso. 
Outra característica que Chico Buarque cria na sua personagem é o fato de esta ser, digamos assim, inculta. Julinho da Adelaide cursou somente até o primeiro ginasial e questionado sobre o motivo da sua parada, ele diz que foi tomar aula na escola da vida - é interessante ressaltar que Mário Prata, Melchíades Cunha Júnior e o próprio Chico Buarque caem na risada depois da resposta. "E daí que eu sei ler e escrever e acho que me exprimo muito bem. Você não está me entendo?” Para um regime autoritário, quanto mais as pessoas forem incultas, mais fácil será dominá-las. Tanto é que um dos primeiros passos de uma ditadura é o de tentar dominar os meios de comunicações, para assim poder manipular a opinião pública. E Chico Buarque fazendo com que Julinho seja assim, faz com que os censores desviem a atenção das suas letras, pois como pode, ou que pretensão tem, alguém que não tem a menor cultura questionar alguma coisa? Creio que nenhuma. Perguntado se também lia jornais, Julinho responde dizendo que "Não, só que o Leonel manda ler... Agora, em geral, ele já dá o serviço todo em vez de mandar ler. Porque sou o criador, entende? Se eu ficar o tempo todo lendo, não vou poder me expressar bem”. Pelo contrário, somente quem lê consegue se expressar e mais além, consegue ter novas idéias. No entanto, são estas idéias que Chico quer que Julinho não tenha. Quanto mais vazia for a personagem Julinho da Adelaide, mais fácil será driblar a censura para Chico Buarque.

Chico Buarque não entra em detalhes a respeito das músicas compostas sob pseudônimo ao longo da entrevista. Julinho da Adelaide apenas se refere a "Milagre Brasileiro" considerando-a como a "mais forte" de todas e que "Acorda Amor" - a qual ele se refere como "Chama o Ladrão" - faz referência a um episódio da vida de Leonel, quando este fora preso, uma vez, pela polícia.

“Acorda Amor", de 1974, foi composta sob o governo Médici e a sua Doutrina de Segurança Nacional. E foi em nome desta ‘doutrina' que levava o brasileiro a viver num clima de tanta insegurança e medo e é esta situação que permeia toda a canção. Preferir ao ladrão a Polícia, mostra claramente esta insegurança. Podemos interpretar os versos "Era e dura / Numa muito escura viatura", como referência à ditadura e aos seus veículos de repressão: "Não é mais pesadelo nada / Tem gente já no vão da escada [...] São os homens", como exemplo das prisões na madrugada: "Mas depois de um ano eu não vindo / Ponha a roupa de domingo/ E pode me esquecer", como os sumiços inexplicados; "Se você corre o bicho pega / Se fica, não sei não"; referência aos impasses, às dúvidas: "Dia desses chega a sua hora", a insegurança; e a solução para o crime político é recorrer ao crime comum: "Chame o ladrão". 
“Jorge Maravilha”, também de 1974, é uma canção puramente irônica. E que, segundo Gilberto Vasconcelos, utiliza-se da "linguagem da fresta", ou seja, uma linguagem metaforizada. Bezerra de Meneses (2000, p. 73) conclui: "que para se pronunciarem coisas, em determinadas situações históricas, só sendo malandro; o otário simplesmente... silenciaria”. E assim é Jorge Maravilha, pura voz de malandro. Chico Buarque, em entrevista a Folha de São Paulo no ano de 1977 diz: "Aconteceu de eu ser detido por agentes de segurança, e no elevador o cara pedir um autógrafo para a filha dele. Claro que não era o delegado, mas aquele contínuo de delegado". E o verso, maravilhosamente construído, "Você não gosta de mim / Mas a sua filha gosta" pode servir para qualquer interpretação. Ora pode ser a filha de um simples trabalhador, ora pode ser a filha do general Médici. Ninguém pode saber.

"Milagre Brasileiro", de 1975, pode ser encarada - no limite do debate - como uma canção 'jornalística'. O governo Médici propalava aos quatro ventos o milagre econômico pelo qual passava o Brasil naquele momento. Milagre, aliás, concentrador de renda, cujo bode expiatório fora a estagnação do salário da grande massa trabalhadora. Podemos considerar os versos "Cadê o meu / Cadê o meu, ó meu? Dizem que você se defendeu / É o milagre brasileiro / Quanto mais trabalho / Menos vejo dinheiro / É o verdadeiro boom / Tu tá no bem bom / Mas eu vivo sem nenhum / Mas, também, se eu fosse eu / Quebrava o teu / Cobrava o meu Direito", conforme Bezerra de Meneses:

como uma tradução dos seguintes dados estatísticos: se, em 1965, para adquirir a ração essencial mínima de sua alimentação, o operário tinha que trabalhar 88 horas e 16 minutos, em 1974, para obter a mesma quantidade de alimentos, ele tinha de gastar o dinheiro ganho em 163 horas e 32 minutos. (MENESES, 2000, p. 18)

Ou seja, "Milagre Brasileiro" pode ser considerada aqui uma espécie de crônica social na medida que se revela a biografia individual do artista.

Porém, nada dura para sempre. Uma reportagem do Jornal do Brasil em 1975 acabou desmascarando Chico Buarque e seu pseudônimo. Fato constrangedor para a Censura, que a partir daquela data passou a exigir CIC e RG junto ao nome do compositor.

Vimos, portanto, que Julinho da Adelaide deixou de ser um simples nome em um papel, uma assinatura, para se constituir em uma personagem daqueles tempos. Uma personagem detalhadamente criada como qualquer personagem literária que Chico, inclusive, viria a criar mais tarde. Uma personagem que criou voz a partir da simulação de uma entrevista, em um claro exercício de criação artística, onde temos a invenção de um novo mundo permeado de diversas histórias. 


\section{Referências}

FONTES, Maria Helena Sansão. Sem fantasia: masculino-feminino em Chico Buarque. Rio de Janeiro: Graphia, 1999.

HOLANDA, Chico Buarque de. Cancioneiro e entrevistas. Disponível em: http://www.chicobuarque.com.br/. Acesso em: 14 de jun. 2004

MENESES, Adélia Bezerra de. Desenho mágico: poesia e política em Chico Buarque. São Paulo: Ateliê, 2000.

PESSOA, Fernando. Ficções do interlúdio: 1914-1935. São Paulo: Companhia das Letras, 1998.

SCHWARZ, Roberto. Ao vencedor as batatas. São Paulo: Duas Cidades/Editora 34, 2003.

SOUZA, Antônio Cândido de Mello e. Literatura e sociedade: estudos de teoria e história literária. São Paulo: Nacional, 1976. 